\title{
Biochemical Studies on the Carotenoids in Porifera. The Structure of Clathriaxanthin in Sea Sponge, Clathria frondifera (Bowerbank)
}

\author{
Yoshito TANAKA* and Teruhisa KATAYAMA* \\ (Received February 24, 1976)
}

\begin{abstract}
A new aromatic keto-carotenoid was isolated from orange sea sponge, Clathria frondifera (Bowerbank), which was shown to be a 3-hydroxy-4-keto-2, 3-didehydro- $\beta, \chi$-carotene. The name clathriacine is proposed for the aromatic keto-carotenoid and clathriaxanthin for the esterified carotenoid.
\end{abstract}

The beautiful yellow, orange and red colors in many sponge like other fish or Crustacea have always attracted biochemists because of their diversity of colors as compared with those present in other land animals, but the metabolism of the carotenoids in sea sponge and its chemistry have not yet been elucidated.

KARRER et al. ${ }^{1)}$ recognized the existence of astaxanthin in red sea sponge, Axinella crista-glli. DRUMm et al. ${ }^{2,3)}$ reported the presence of echinenone, $\gamma$-carotene in Hymeniacidon sanguineum. In $1957 \mathrm{YAMAGUCHI}^{4}$ first isolated the aromatic carotenoids, renieratene, isorenieratene and renierapurprin from Reniera japonica.

The existence of mono-hydroxy- $\beta$-isorenieratene and $\beta$-isorenieratene was recently reported by $\mathrm{SMITH}^{\text {s) }}$.

We report on the existene and structure of a heretofore undescribed aromatic ketocarotenoid: clathriaxanthin. This carotenoid is a major carotenoid (ca $55 \%$ of total carotenoids) of the orange color sea sponge, Clathria frondifera (Bowerbank).

\section{Materials and Methods}

The orange sea sponge were collected at Kinko Bay, Kagoshima and the carotenoids were extracted with acetone in a Waring blender. The solid matters were separated by filtration and reextracted until no further pigments were obtained. The carotenoids were transferred to petroleum ether from acetone with water. The petroleum ether solution of the crude carotenoids was washed with water to remove acetone, dried over anhydrous sodium sulphate, and evaporated under reduced pressure. The esterified carotenoids and carotenes were initially separated preparatively by chromatography on a magnesium oxide column (magnesium oxide: Hyflo Super $\mathrm{Cel}=1: 2$ ). The pigment solution was placed on the column in petroleum ether and developed with $30 \%$ acetone in petroleum ether.

* Laboratory of Marine Biochemistry, Faculty of Fisheries, University of Kagoshima, 4-5-20, Shimoarata, Kagoshima, Japan（田中淑人・片山輝久：鹿児島大学水産学部海洋生物化学数室） 
The seven resulting bands were obtained and the reddish main band was eluted with $10 \%$ acetic acid in ethyl ether. The carotenoids were transferred to petroleum ether by the addition of water. The petroleum ether solution of the carotenoids was repeatedly washed with water to remove trace of acetic acid, dried over anhydrous sodium sulphate, and evaporated under reduced pressure. The carotenoids which were thus extracted were rechromatographed on a dried powdered sugar column, using petroleum ether as a developing solvent. Three bands were obtained and the main pinkish band was eluted with acetone. The carotenoid was transferred to petroleum ether from acetone with water and evaporated

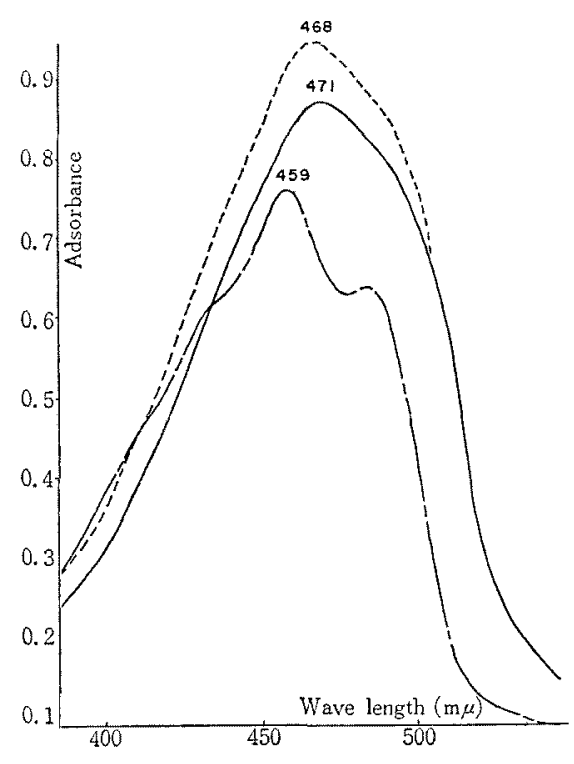

Fig. 1. The absorption spectra of clathriacine. Solid curve: in petroleum ether Dotted curve: in ethanol Dashed curve: after reduction to dryness under vacuum. Thus obtained pigment was saponified by dissolving it in $100 \mathrm{~m} l$ of absolute ethyl alcohol, adding $10 \mathrm{ml}$ of $60 \%(\mathrm{w} / \mathrm{v})$ aqueous potassium hydroxide and leaving it overnight under nitrogen at room temperature ${ }^{6)}$. The saponified pigment was transferred to petroleum ether with water, dried over anhydrous sodium sulphate and concentrated under vacuum. The pigment was repurified on a sugar column, using petroleum ether as developing solvent. Only one band was obtained. The isolated pigment was crystallized from n-hexane-ethyl ether and had the following characteristics: m.p. $172-173^{\circ} \mathrm{C}$, $\lambda$ max in petroleum ether $471 \mathrm{mn}$ (Fig. $1)$.

The pigment was reduced by the addition of sodium borohydride to a solution of the pigment in ethyl alcohol at $5^{\circ} \mathrm{C}$. The reaction was allowed to proceed for 30 minutes. The absorption spectrum of the reduced pigment was shown in Fig. 1. The crystalline pigment was ground with potassium bromide, passed into a pellet and the infrared spectrum measured in a IR-spectrophotometer (Fig. 2). Characteristic absorption bands were obtained at $3440 \mathrm{~cm}^{-1}$ (hydroxyl), $1620 \mathrm{~cm}^{-1}$ (carboxyl) and $975 \mathrm{~cm}^{-1}$ (trans double bonds).

The NMR spectrum of the pigment was obtained at $100 \mathrm{MHz}$ and was determined in $\mathrm{CDCl}_{3}$ relative to internal TMS (Fig. 3). The NMR spectrum revealed C-methyl resonances at $\tau 7.75$ and 7.84 , indicating the aromatic end group of renierapurpurin. ${ }^{7,8}$ There was only one signal as geminal methyl at $\tau 8.75$ and it shows one end group has a geminal methyl, but another has no geminal methyl. 


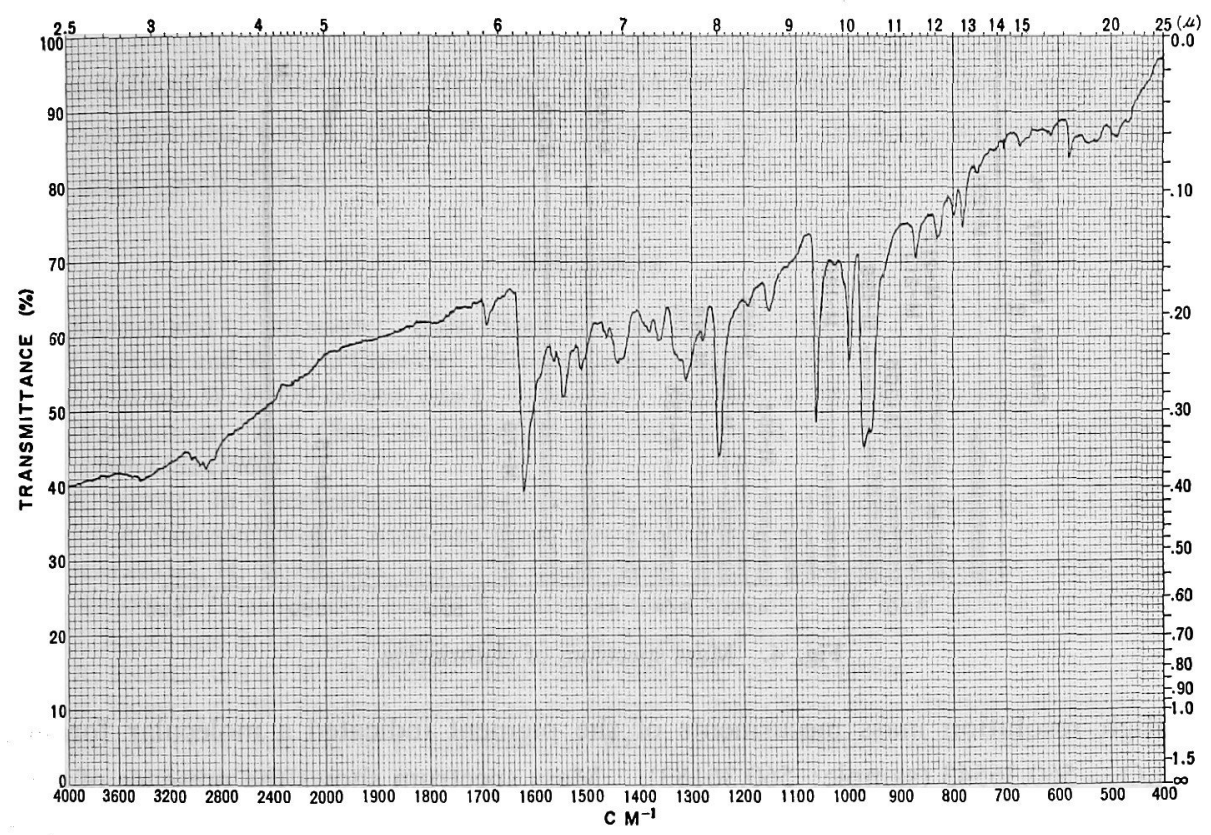

Fig. 2. Infrared spectrum of clathriacine.

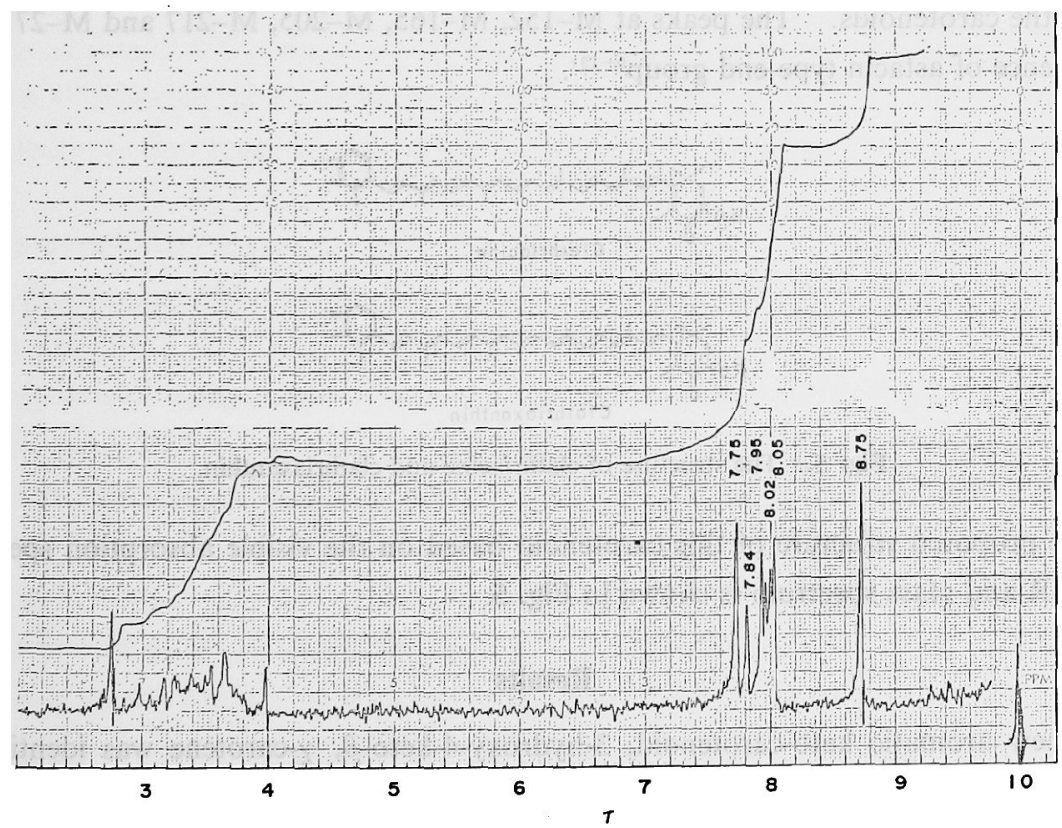

Fig. 3. NMR spectrum of clathriacine. 


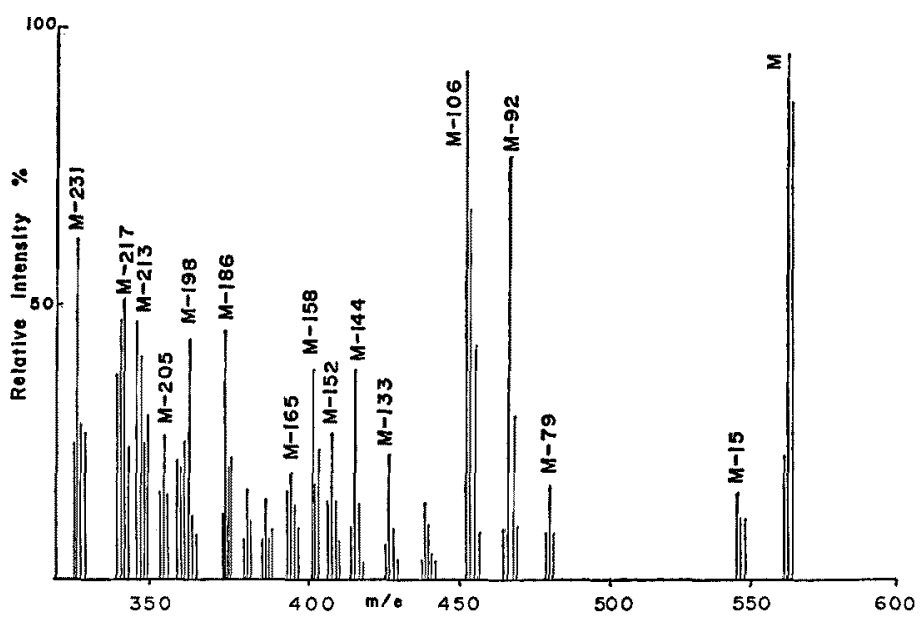

Fig. 4. Mass spectrum of clathriacine.

High resolution mass mesurments of the pigment indicated a molecular formula: $\mathrm{C}_{40} \mathrm{H}_{48} \mathrm{O}_{2}=560.36543$ (sample: 560.36183 ). Mass spectrum shows the presence of peaks at M-2, M-92, M-106, M-133 and M-152 (Fig. 4). The peak at M-133 shows the existence of the carotenoids having the aromatic end group such as isorenieratene, renierapurpurin, chlorobactene and okenone ${ }^{9,12)}$. The peaks at M-92 and M-106 are typical ones of the carotenoids. The peaks at M-152, M-165, M-205, M-217 and M-271 show the presence of astacin type end group ${ }^{9-12)}$

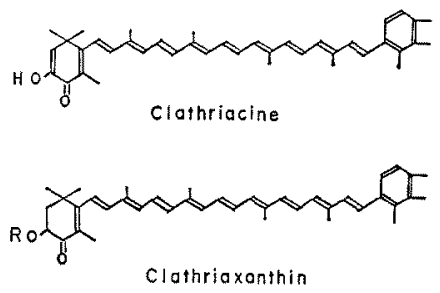

Fig. 5. The structure of clathriacine and clathriaxanthin.

The proposed structure of this carotenoid based on the visible absorption spectrum, IR, NMR and mass spectrum is shown in Fig. 5.

\section{Results}

A new aromatic keto-carotenoid, 3-hydroxy-4-keto- $\beta, \chi$-carotene was identified in orange sea sponge, and the name clathriaxanthin was proposed. 


\section{Acknowledgements}

The authors are indebted to Dr. Senji TANIDA for identification of the sample, orange sea sponge and also wish to thank Prof. S. IsHIO and Dr. T. YANO at Kyushu University for the mass spectral data.

\section{References}

1) P. Karrer and U. Solmssen: Helv. Chim. Acta. 18, $915-921$ (1935).

2) P. J. Drumm and W. F. O'Connor: Nature, Lond., 145, 425 (1940).

3) P. J. Drumm, W. F. O'Connor, and L. P. Renouf: Biochem. J. 39, 208-210 (1945).

4) M. Yamaguch: Bull. Chem. Soc. Japan, 30, 111-114 (1957): 31, 51-55 (1958): 32, 1171-1173 (1959): 33, $1560-1562(1960)$.

5) V. E. SMTTH: In "Biochemical and Biophysical Perspectives in Marine Biology" (ed. D. C. Maline and J. R. Sargent), Vol. 1, Academic Press, New York, 1974, pp. 189-190.

6) T. Katayama, H. Yoxoyama, and C. O. Chichester: Int. J. Biochem. 1, 438-444 (1970).

7) H. KJosen, S. Liaaen-Jensen, and C. R. Enzell: Acta Chem. Scan. 25, 85-93 (1971).

8) A. J. AAsEn and S. LIAAEN-JEnSEN: Acta Chem. Scan. 21, 970-982 (1967).

9) C. R. Enzell and G. W. Francis: Acta Chem. Scan. 23, 727-750 (1969).

10) C. R. Enzell, G. W. Francis, and S. LlaAen-Jensen: Acta Chem. Scan. 22, 344-347 (1968).

11) J. Baldas, O. N. Porter, A. P. Leftwick, H. Ruth, B. C. L. Weedon, and J. Szabolos: Chem. Comm. 415-416 (1969).

12) W. Vetter, G. ENGLeRT, N. RIGASSI, and U. SchwIEtER: "Spectroscopic methods", in Carotenoids (ed. O. ISLER), Birkhauser Verlag, Basel, Switzerland, 1971, pp. 189-266. 